\title{
A New Approach to Fault Detection in the Power Converter in Wind Turbine Conversion Systems
}

\author{
Abada Zhour a,1, Ghoudelbourk Sihem b,2, DIB Djalel a,3,* \\ a Department of Electrical Engineering, Laboratory of Mine LM, Larbi Tebessi University of Tebessa, 12002, Algeria \\ ${ }^{\mathrm{b}}$ Department of Electrical Engineering, University BadjiMokhtar of Annaba, 23000, Algeria \\ ${ }^{1}$ zhour_abada@yahoo.fr, ${ }^{2}$ sghoudelbourk@yahoo.fr, ${ }^{3}$ dibdjalel@gmail.com \\ * Corresponding Author
}

\section{ARTICLE INFO}

Article history

Received

Revised

Accepted

Keywords

Doubly-Fed Induction;

Generator;

Short Circuit;

Inverter;

Fault Detection;

FDMSC;

Power converter;

\begin{abstract}
The detection of faults in a wind turbine chain is of prime importance in order to maintain safety, enhance reliability and improve economic performance. In addition, wind systems have to ensure a continuity of service for a considerable period of time in the event of an electrical fault in the network or a fault in one of the elements of the electromechanical conversion system. This paper presents a fault detection methodology of the power converter within a wind turbine chain, equipped with a Doubly-Fed Induction Generator (DFIG). A configurable, fast, and accurate scheme is developed, the basis of which is the reliable identification of the failed switch. The solution proposed in this work involves the deployment of a redundant arm in the event of a fault; the replacement arm is utilized while waiting for a maintenance or repair operation to be carried out. The approach developed in this paper provides continuity of service after the occurrence of a fault in the network system and fault detection time is reduced. The validity of the proposed identification methodology is assessed by means of simulation of the model of a wind turbine conversion system.
\end{abstract}

This is an open-access article under the CC-BY-SA license.

\section{Introduction}

Currently, because of the diminishing reserves of fossil fuels, many countries around the world are shifting to renewable energy resources in order to produce electricity. Wind energy is one of the fastest-growing energy sources throughout the world. A study carried out in 2017 in [1] revealed a growth of 10 percent in cumulative installed capacity, compared to the previous year, Wind Power Capacity reaches 539 GW, 52,6 GW added in 2017. This is the thirdlargest number ever installed within one year, after the record years 2015 and 2014.

As the power from installed wind turbines increases on a year-by-year basis, energy suppliers can no longer tolerate a disruption in the supply of energy due to failures (electrical or electromechanical faults) in generating equipment. The need to maintain a stable network has led them to look for ways to mitigate the effects of these failures. The defects that may arise 
in the electromechanical conversion chain are largely due to the failure of control elements in close proximity to the converters or the power component itself (IGBT type). This defect can lead to a total or partial loss of phase current control [2]. Moreover, if the fault is not detected and repaired quickly, the resulting damage to the converters will almost certainly lead to a malfunction of the entire wind generation system. Such a failure will require the disconnection of the wind generator from the network and a consequential loss of service until a repair and maintenance operation can be carried out.

Recently, the behave us of static converters during the failure of a power semiconductor has been the topic of many academic publications. These include the work introduced in [3], involving a methodology based on the use of additional voltage sensors for the detection of open-circuit or short-circuit faults. It was shown in this study that the measurement of the three voltages between each phase of the converter and the midpoint of the two capacitors of the continuous source, thereby facilitating a comparison with estimated voltages, allowing the fault to be detected in a quarter of the period of the fundamental phase currents.

Table 1 lists the detection time for the various methods described above when applied to an electrical machine. As shown, the number of additional sensors is the same for all methods, according to many academic publications.

Table 1. Comparisons of fault detection methods

\begin{tabular}{clcc}
\hline $\begin{array}{c}\text { Principal of the method, } \\
\text { according to many publications }\end{array}$ & $\begin{array}{c}\text { Application } \\
\text { domain }\end{array}$ & $\begin{array}{c}\text { Detection } \\
\text { time }\end{array}$ & $\begin{array}{c}\text { Number of additional } \\
\text { sensors }\end{array}$ \\
\hline$[3]$ & Electrical machine & $>5 \mathrm{~ms}$ & 3 \\
\hline$[4]$ & Electrical machine & $>5 \mathrm{~ms}$ & 3 \\
\hline$[5][6]$ & Electrical machine & $>5 \mathrm{~ms}$ & 3 \\
\hline$[7]$ & Electrical machine & $10 \mu \mathrm{s}$ & 3 \\
\hline$[8]$ & Electrical machine & $10 \mu \mathrm{s}$ & 3 \\
\hline
\end{tabular}

In [4], the voltages measured at the terminals of the switches, mainly at the bottom of each arm, were used to detect defects. In addition, the above study demonstrated how these measured voltages and their comparisons with a threshold allowed the fault to be detected in a quarter of the period of the phase currents.

Moreover, ref. [5][6] introduces a scheme that involves close commands (or "drivers") for each of the arms of the converter incorporating a circuit for detecting short-circuits faults. The driver rapidly detects the fault, and at the opening, the semiconductors of the short-circuited arm impose their control commands at zero.

In [7], a method implemented in the drivers has been proposed for the detection of a shortcircuit occurring in an arm. This is based upon an approach that is applicable to all industrial drivers: the measurement of the voltage drops at the terminals of the switches. The time response for this protection, typically being a few microseconds, is usually configurable and adjustable by discrete components that are external to the driver. In a practical situation, the voltage error cannot be zero at all times because of the voltage drops at the terminals of the switches, these being due to the effects of the switching and the blackouts of the drivers. Thus, the voltage error is characterized by peaks. If these peaks are not filtered, then a fault can be detected during a commutation.

The work presented in [8] involves an approach that uses an additional time criterion to perform the filtering. In order to avoid these detection errors due to the commutation of the switches, this study proposes transforming the voltage error signal into a time error signal.

In this work, we will first propose a new and fast technique for detecting a fault in one of the semi-conductors of a three-phase converter with a voltage structure without additional sensors. 
The case of short-circuit failure in one of the power semiconductor switches will be considered. A graphical methodology to identify the faulty switch will be proposed which is based on the shape recognition of the vector trajectory of the voltages in the axes $\alpha \& \beta$ at the output of the converter, where a defect can be detected in less than $3 \mu$ s with a significant reduction in the detection time. The fault detection method of short-circuit FDMSC in semi-conductors is obtained by the identification of the signals. This method is based on the control laws that consequently allow the optimal working of the wind turbine. Throughout this paper, the following notations are used.

\section{Method Proposed}

\subsection{DFIG Modelling}

The DFIG is used in onshore wind farms. The main advantage of this machine is the fact that this DFIG has its three-phase static converters sized for a part of its nominal power. Indeed, the DFIG allows a range of operation of $\pm 30 \%$ around the synchronous speed, which consequently guarantees a reduced dimensioning of the static converters, as the latter are connected between the rotor coil of the DFIG and the electrical network [9]. The three-phase static converters with a voltage structure are the essential elements in the electromechanical conversion chain of a wind energy conversion system. This is due to the fact that these converters enable the control of the active and reactive power injected into the electrical network as a function of the wind speed applied to the turbine blades. Fig. 1 seen the variable speed wind system and Table 2 presents the nomenclatures. The turbine drives the DFIG are equipped with rings or brush systems through a multiplier, which is directly connected to the electrical network by the stator $[10][11]$.

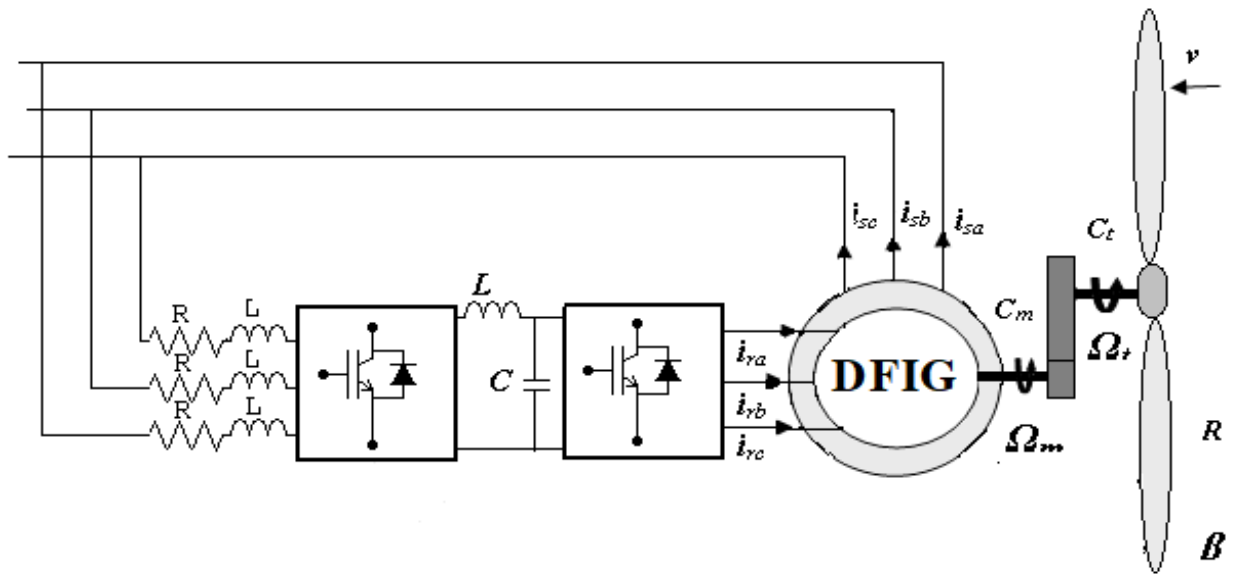

Fig. 1. DFIG based wind turbine connected to the grid

Table 2. Nomenclature

\begin{tabular}{cc}
\hline $\boldsymbol{\Omega} \boldsymbol{m}$ & Mechanical speed of DFIG (rpm) \\
\hline $\boldsymbol{\Omega} \boldsymbol{t}$ & Speed of rotation of turbine $(\mathrm{rpm})$ \\
\hline $\boldsymbol{R} \boldsymbol{s}, \boldsymbol{R} \boldsymbol{r}$ & Mechanical torque of DFIG (Nm) \\
\hline $\boldsymbol{l}, \boldsymbol{r} \boldsymbol{r}$ & Stator and rotor winding resistances \\
\hline $\boldsymbol{M} \boldsymbol{s}, \boldsymbol{M r}$ & The inductance of the stator and rotor windings \\
\hline $\boldsymbol{J}$ & Mutual inductances \\
\hline $\boldsymbol{p}$ & Rotor moment of inertia \\
\hline $\boldsymbol{P}, \boldsymbol{Q} \boldsymbol{s}$ & Number of pole pairs \\
\hline $\boldsymbol{P r}, \boldsymbol{Q} \boldsymbol{r}$ & Static active and reactive power \\
\hline $\boldsymbol{\omega} \boldsymbol{s}, \boldsymbol{\omega r}$ & Rotor active and reactive power \\
\hline
\end{tabular}


The rotor of the DFIG is powered through a static three-phase converter. Independent control of the active power and reactive power is carried out [12]. The equations of the stator and rotor voltages of the DFIG in the Park reference frame are expressed as follows [13][14]

$$
\left\{\begin{array}{l}
V_{s d}=R_{s} I_{s d}+\frac{d \phi_{s d}}{d t}-\dot{\theta}_{s} \phi_{s q} \\
V_{s q}=R_{s} I_{s q}+\frac{d \phi_{s q}}{d t}+\dot{\theta}_{s} \phi_{s d} \\
V_{r d}=R_{r} I_{r d}+\frac{d \phi_{r d}}{d t}-\dot{\theta}_{r} \phi_{r q} \\
V_{r q}=R_{r} I_{r q}+\frac{d \phi_{r q}}{d t}+\dot{\theta}_{r} \phi_{r d}
\end{array}\right.
$$

Under the assumption that magnetic circuits are linear and mutual inductances equal while neglecting iron losses, the magnetic equations are given by

$$
\left\{\begin{array}{l}
\phi_{s d}=L_{s} I_{s d}+M I_{r d} \\
\phi_{s q}=L_{s} I_{s q}+M I_{r q} \\
\phi_{r d}=L_{r} I_{r d}+M I_{s d} \\
\phi_{r q}=L_{r} I_{r q}+M I_{s q}
\end{array}\right.
$$

The mechanical equation of the machine is given by

$$
J \frac{d \Omega}{d t}=T_{e m}-T_{r}-f \Omega
$$

And the electromagnetic torque, $\mathrm{T}_{\mathrm{em}}$ is

$$
T_{e m}=p \frac{M}{L_{s}}\left(I_{r d} \phi_{s q}-I_{r q} \phi_{s d}\right)
$$

In order to ensure decoupling between the stator and the rotor, it is can to orient the stator flux along the $\mathrm{d}$-axis of the rotating reference frame

$$
\phi_{s d}=\phi_{s} \quad \text { and } \quad \phi_{s q}=0
$$

And

$$
T_{e m}=-p \frac{M}{L_{s}} I_{r q} \phi_{s d}
$$

Using equation (5), the flux equation (2) can be re-written as

$$
\left\{\begin{array}{c}
\phi_{s d}=L_{s} I_{s d}+M I_{r d} \\
0=L_{s} I_{s q}+M I_{r q}
\end{array}\right.
$$

If the stator windings resistance is neglected, the two first equations of (1) become

$$
\left\{\begin{array}{l}
V_{s d}=\frac{d \phi_{s}}{d t} \\
V_{s q}=\omega_{s} \phi_{s}
\end{array}\right.
$$

Consequently,

$$
\left\{\begin{array}{l}
V_{s d}=0 \\
V_{s q}=\omega_{s} \phi_{s}=V_{s}
\end{array}\right.
$$


By using equation (2), one can show that

$$
\left\{\begin{array}{c}
I_{s d}=-\frac{M}{L_{s}} I_{r d}+\frac{\phi_{s}}{L_{s}} \\
I_{s q}=-\frac{M}{L_{s}} I_{r q}
\end{array}\right.
$$

Knowing that the equations of the stator active power and stator reactive power are

$$
\left\{\begin{array}{l}
P_{s}=V_{s d} I_{s d}+V_{s q} I_{s q} \\
Q_{s}=V_{s q} I_{s d}-V_{s d} I_{s q}
\end{array}\right.
$$

By using equation in (9), equation (11) are reduced as

$$
\left\{\begin{array}{l}
P_{s}=V_{s} I_{s q} \\
Q_{s}=V_{s} I_{s d}
\end{array}\right.
$$

Substituting the equation for the currents given in (10) into (12), it can be seen that

$$
\left\{\begin{array}{l}
P_{s}=-V_{s} \frac{M}{L_{s}} I_{r q} \\
Q_{s}=-V_{s} \frac{M}{L_{s}} I_{r d}+V_{s} \frac{\phi_{s}}{L_{s}}
\end{array}\right.
$$

And from equation of (9), the following relation is obtained

$$
\phi_{s}=\frac{V_{s}}{\omega_{s}}
$$

Therefore, equation (13) can be re-written as

$$
\left\{\begin{array}{l}
P_{s}=-V_{s} \frac{M}{L_{s}} I_{r q} \\
Q_{s}=-V_{s} \frac{M}{L_{s}} I_{r d}+\frac{V_{s}^{2}}{L_{s} \omega_{s}}
\end{array}\right.
$$

Expressions (15) show that the stator power $P_{s}$ is proportional to $I_{r q}$ and the stator reactive power is not proportional to $I_{r d}$ due to a constant imposed by the network. Thus, these stator powers $P_{s}$ and $Q_{s}$ can be controlled independently of each another and the relationship between the rotor currents and the rotor voltages as:

$$
\left\{\begin{array}{l}
\phi_{r d}=\left(L_{r}-M^{2}\right) I_{r d}+\frac{M V_{s}}{L_{s} \omega_{s}} \\
\phi_{r q}=\left(L_{r}-\frac{M^{2}}{L_{s}}\right) I_{r q}
\end{array}\right.
$$

By replacing both equations of (16) in (1), the following expressions are obtained

$$
\left\{\begin{array}{c}
V_{r d}=R_{r} I_{r d}+\sigma L_{r} \frac{d I_{r d}}{d t}-s \sigma \omega_{s} L_{r} I_{r q} \\
V_{r q}=R_{r} I_{r q}+\sigma L_{r} \frac{d I_{r q}}{d t}+s \sigma \omega_{s} L_{r} I_{r d}+s \frac{M V_{s}}{L_{s}}
\end{array}\right.
$$

Or 


$$
\left\{\begin{array}{l}
V_{r d}=R_{r} I_{r d}+\sigma L_{r} \frac{d I_{r d}}{d t}-e_{r q} \\
V_{r q}=R_{r} I_{r q}+\sigma L_{r} \frac{d I_{r q}}{d t}+e_{r d}+e_{\varnothing}
\end{array}\right.
$$

with

$$
\sigma=1-\frac{M^{2}}{L_{s} L_{r}} \text { and }\left\{\begin{array}{l}
e_{r q}=s \sigma \omega_{s} L_{r} I_{r q} \\
e_{r d}=s \sigma \omega_{s} L_{r} I_{r d} \\
e_{\varnothing}=s \frac{M V_{s}}{L_{s}}
\end{array}\right.
$$

Equation (18) can be re-written as

$$
\left\{\begin{array}{l}
V_{r d}+e_{r q}=R_{r} I_{r d}+\sigma L_{r} \frac{d I_{r d}}{d t} \\
V_{r q}-e_{r d}-e_{\emptyset}=R_{r} I_{r q}+\sigma L_{r} \frac{d I_{r q}}{d t}
\end{array}\right.
$$

Fig. 2 shows the block diagram of the DFIG. It can be observed the $d$ and $q$ axes can be controlled separately with their own controllers [15].
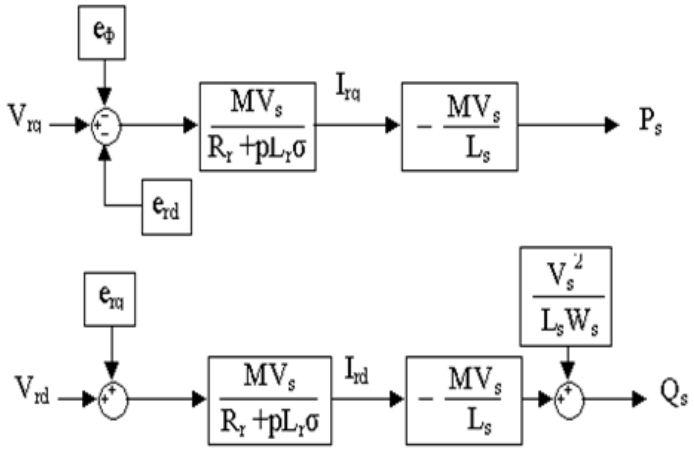

Fig. 2. Block diagram of the DFIG

\subsection{DFIG Control}

In order to independently control the active and reactive powers, the employed control strategy involves the setting of placing a regulation loop on each power component with a PI regulator, as depicted in Fig. 3. Because of the low slip value, the coupling terms between both control axes can be neglected and [16][17].

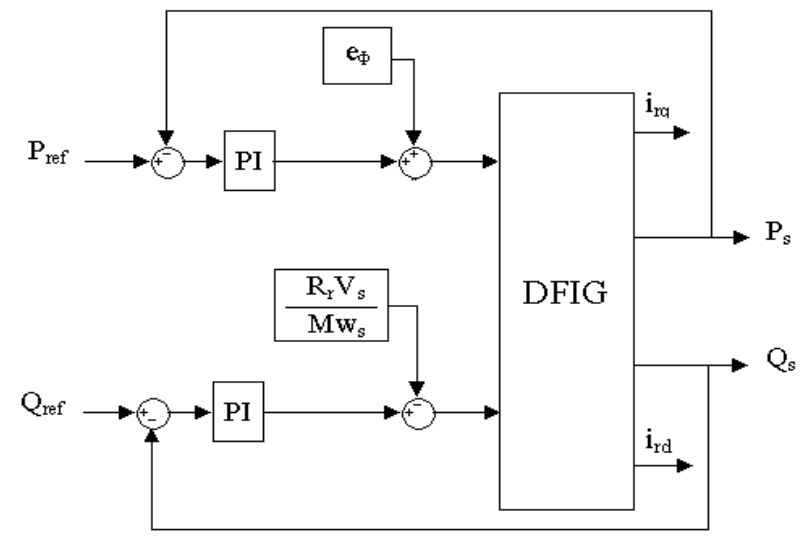

Fig. 3. Block diagram of separate control of active and reactive powers 
The separate active and reactive power control using conventional can be seen in Fig. 4. It can be noticed that the active and reactive powers follow the reference values, and any change on one of these values does not influence the other.

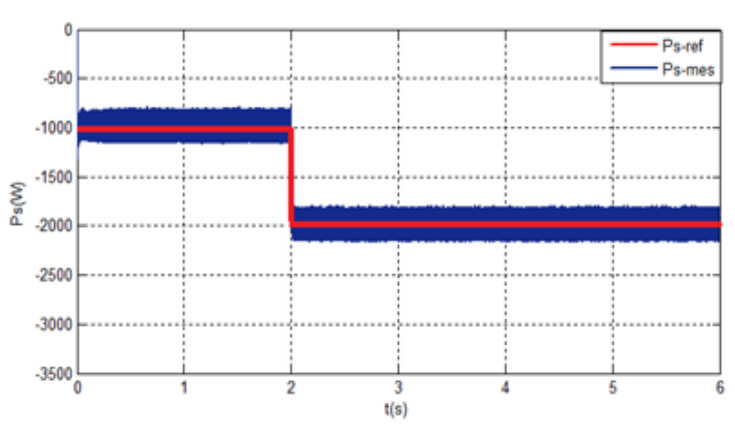

(a)

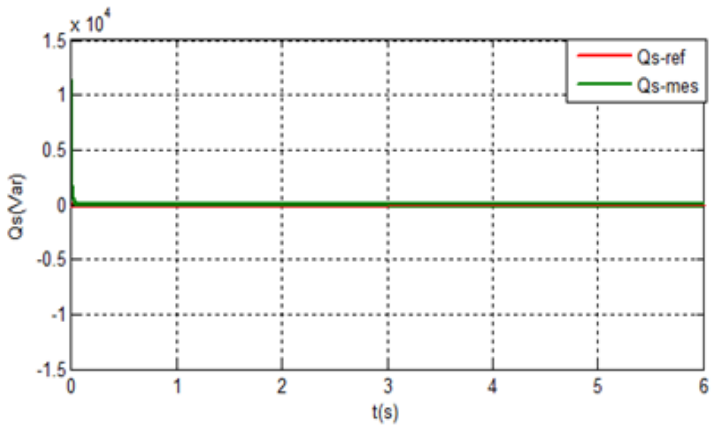

(b)

Fig. 4. (a) Power control of active and (b) reactive powers

Fig. 5 shows the internal structure of the inverter on the rotor side. Fig. 6 depicts the trajectory of the voltages $U_{\alpha}$ and $U_{\beta}$ at the inverter output.

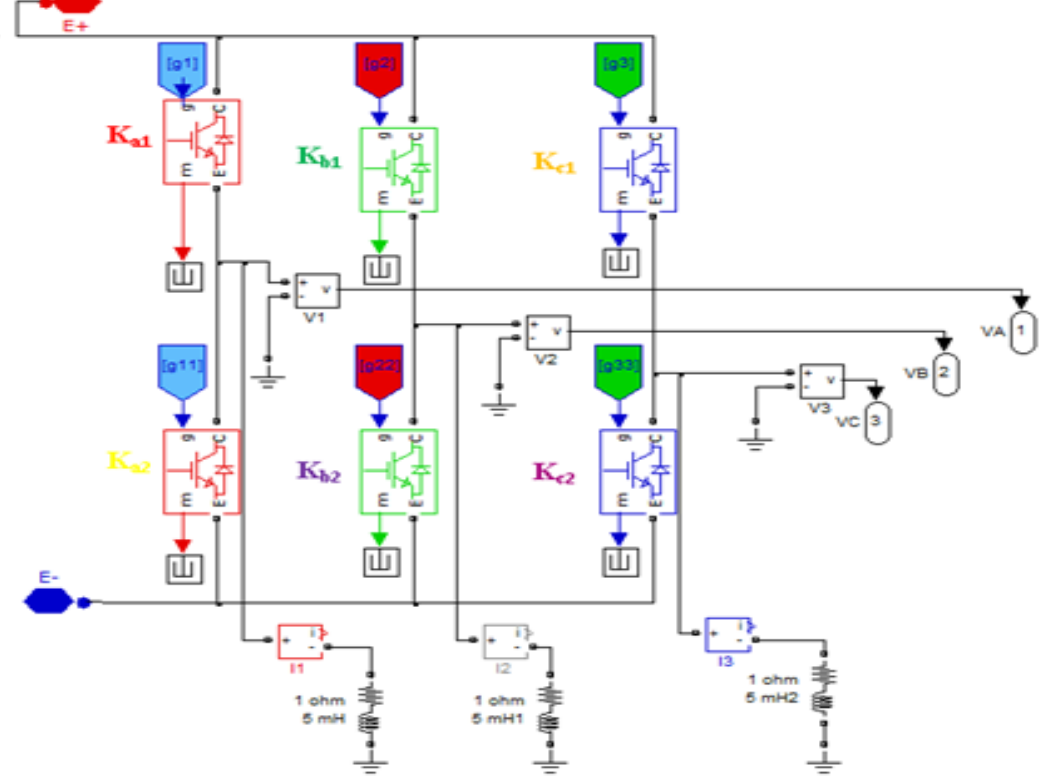

Fig. 5. Structure two-level PWM inverters on the rotor side

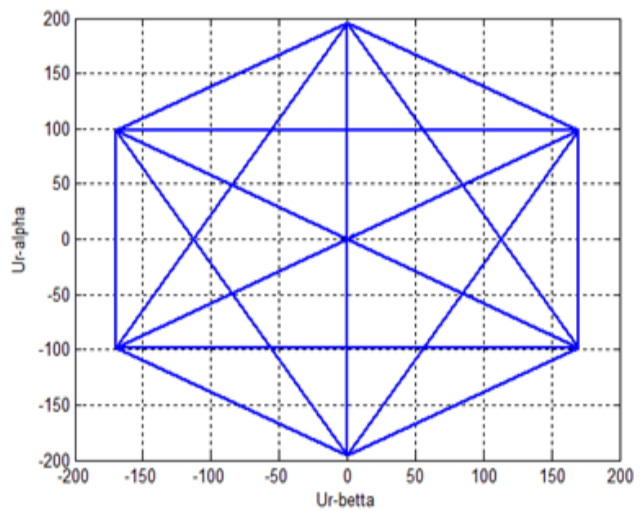

Fig. 6. Signal of $U_{\alpha}=f\left(U_{\beta}\right)$ at the inverter output 


\section{Short-Circuit Fault Detection}

This section presents a short-circuit fault at arm due to a failure of its switches witches of the power converter, within a wind turbine chain, equipped with a Doubly-Fed Induction Generator (DFIG). There depicted the signal $\mathrm{U}_{\alpha}=\mathrm{f}\left(\mathrm{U}_{\beta}\right)$ at the inverter output directly connected to the rotor of the DFIG, and this signal varies according to different types of short-circuits.

This section presents a short-circuit fault at the half arm due to a failure of its switch. In Fig. $7(\mathrm{a})$, as to Fig. 7(f) are depicted the signal $\mathrm{U}_{\alpha}=\mathrm{f}\left(\mathrm{U}_{\beta}\right)$ at the inverter output directly connected to the rotor of the DFIG, and this signal varies according to different types of short-circuits. Each of these figures tells us exactly which switch is short-circuited. Table 3 and Table 4 illustrate DFIG and turbine parameters, respectively, which have been used throughout this work. This approach is fast as it requires only one period of the fundamental phase voltages in order to detect the fault. Subsequently, all six configurations are combined in a unique arrangement, as shown in Fig. 8 and Table 5.

Table 3. The DFIG parameters

\begin{tabular}{cc}
\hline Parameters DFIG & Values \\
\hline Nominal power & $20 \mathrm{KW}$ \\
\hline Rated Frequency & $50(\mathrm{~Hz})$ \\
\hline Number of pole pair & 2 \\
\hline Coefficient of friction & $0.0024 \mathrm{~N} . \mathrm{m} . \mathrm{s}-1$ \\
\hline Moment of inertia of the rotor of the machine & $0.53 \mathrm{Kg} \cdot \mathrm{m}^{2}$ \\
\hline Stator Resistance & $0.455 \Omega$ \\
\hline Rotor Resistance & $0.19 \Omega$ \\
\hline Stator Leakage Inductors & $0.07 \mathrm{H}$ \\
\hline Rotor Leakage Inductors & $0.0213 \mathrm{H}$ \\
\hline Mutual Inductance & $0.034 \mathrm{H}$ \\
\hline
\end{tabular}

Table 4. The turbine parameters

\begin{tabular}{cc}
\hline Parameters & Values \\
\hline $\mathrm{P}$ & $20 \mathrm{KW}$ \\
\hline vnom & $12(\mathrm{~m} / \mathrm{s})$ \\
\hline$\rho$ & $1.22(\mathrm{Kg} / \mathrm{m} 3)$ \\
\hline $\mathrm{R}$ & $3.6(\mathrm{~m})$ \\
\hline Tpmax & 0.475 \\
\hline $\mathrm{G}$ & 6 \\
\hline
\end{tabular}

Table 5. Detection of Short Circuited by Segment

\begin{tabular}{ccccccc}
\hline Seg. AC & Seg. FD & Seg. AE & Seg. DB & Seg. EC & Seg. BF & Short circuited \\
\hline 1 & 1 & 1 & 1 & 1 & 1 & Not fault \\
\hline 1 & 0 & 0 & 0 & 0 & 0 & $\mathrm{~K}_{\mathrm{a} 1}$ \\
\hline 0 & 1 & 0 & 0 & 0 & 0 & $\mathrm{~K}_{\mathrm{a} 2}$ \\
\hline 0 & 0 & 1 & 0 & 0 & 0 & $\mathrm{~K}_{\mathrm{b} 1}$ \\
\hline 0 & 0 & 0 & 1 & 0 & 0 & $\mathrm{~K}_{\mathrm{b} 2}$ \\
\hline 0 & 0 & 0 & 0 & 1 & 0 & $\mathrm{~K}_{\mathrm{c} 1}$ \\
\hline 0 & 0 & 0 & 0 & 0 & 1 & $\mathrm{~K}_{\mathrm{c} 2}$ \\
\hline
\end{tabular}

\section{Results and discussion}

Fig. 9 shows simulation results of the active and reactive powers when a short-circuit fault occurs in the switch $K_{a 1}$ of arm 1 of the converter on the rotor side. At the time $t=5 \mathrm{~s}$, it is evident that the electrical protection of the wind turbine will react before these currents reach excessively high values, thus putting the wind system out of order in order to avoid any deterioration of the electrical equipment. This particular case shows the impact of the variations of the powers generated by this type of fault when the electrical protections of the wind turbine did not work properly. When a fault occurs in one of the rotor-side converter power 
semiconductors, it must be detected as quick as possible and the defective arm must be isolated immediately.

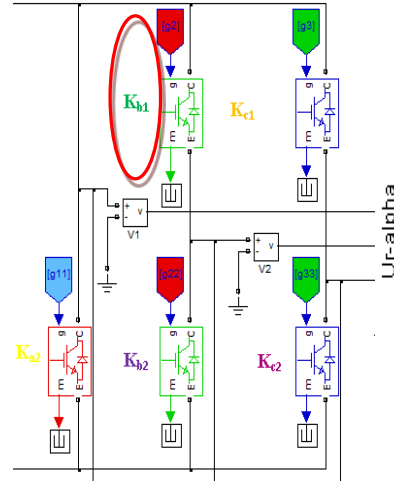

(a)

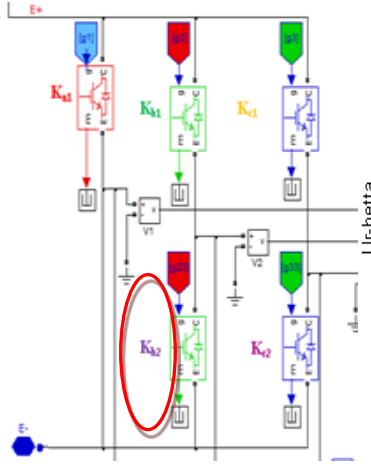

(b)

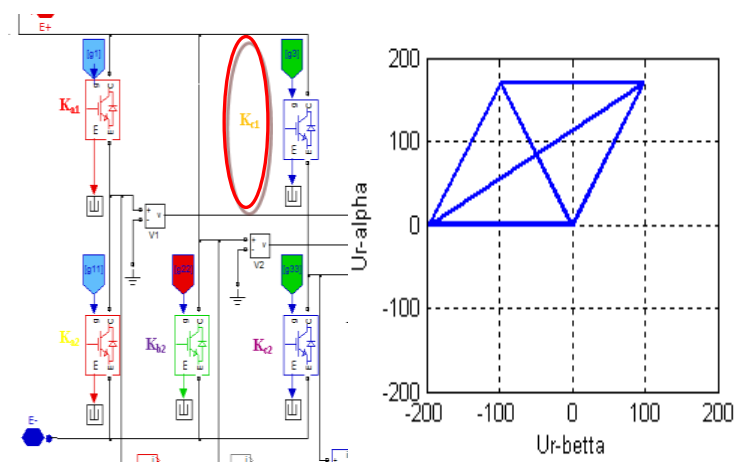

(c)

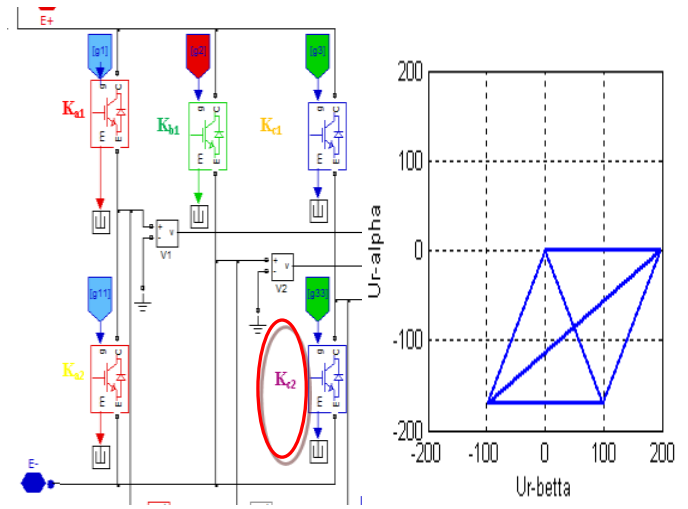

(d)
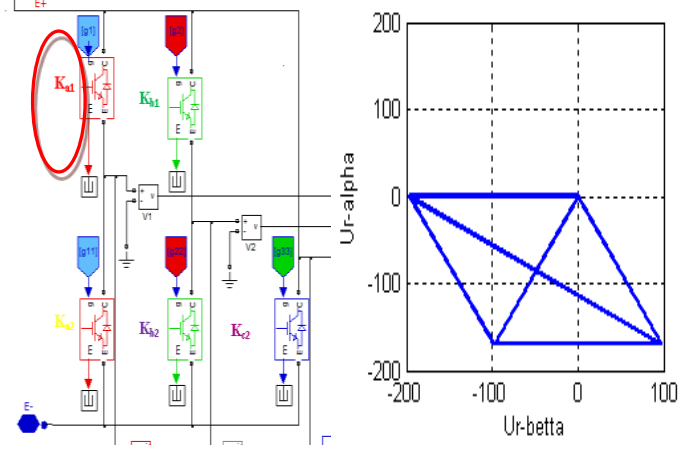

(e)
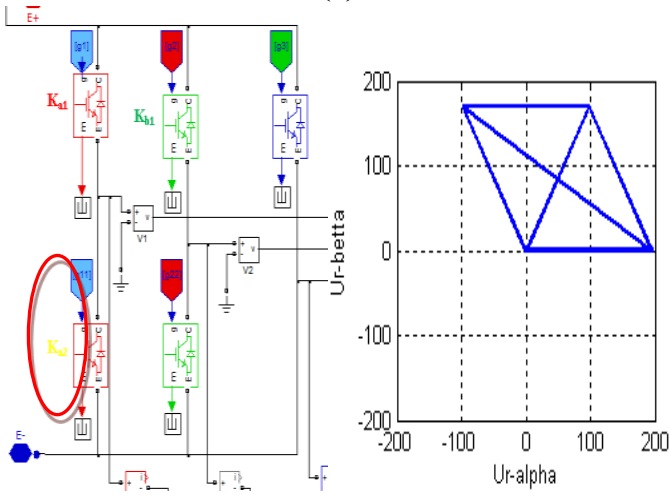

(f)

Fig. 7. (a), (b), (c), (d), (e) and (f) show short-circuits of $K_{b 1}, K_{b 2}, K_{c 1}, K_{c 2}, K_{a 1}$, and $K_{a 2}$, respectively

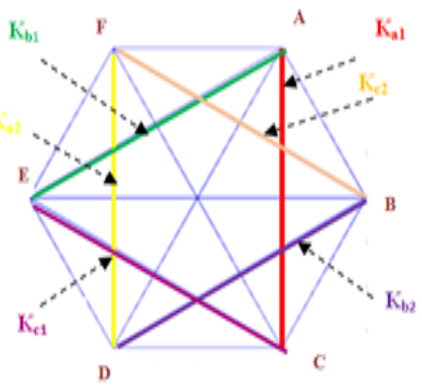

Fig. 8. Fault detection by segment 


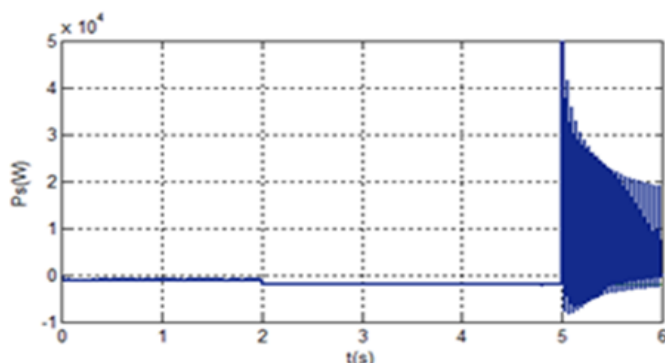

(a)

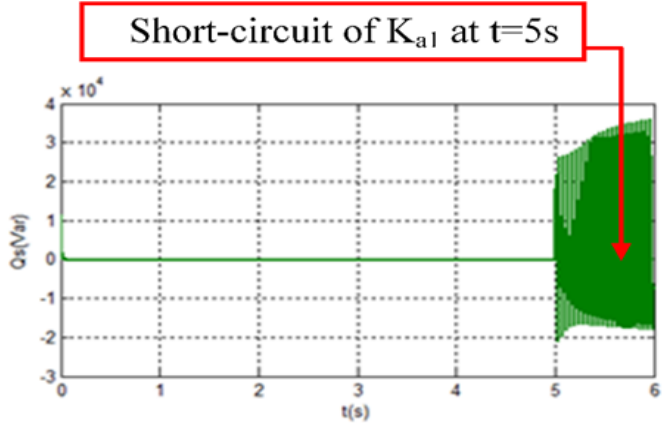

(b)

Fig. 9. (a) and (b) illustrate the active and reactive powers, respectively

If the detected fault is a short circuit, the defective arm is either isolated by the driver that constantly monitors the operation of the switches or by fast fuses connected in series with each switch of the faulty arm. After the fault detection and isolation of the faulty arm, a reconfiguration module controls the bidirectional voltage and current switches $K a, b, c 1$ and $K a, b, c 2(k=\{1,2,3\})$ connected to the defective arms 1 or 2 for the redundant arm topology. By closing these switches, the faulty phase is connected to the midpoint of the redundant arm, as shown in Fig. 10.

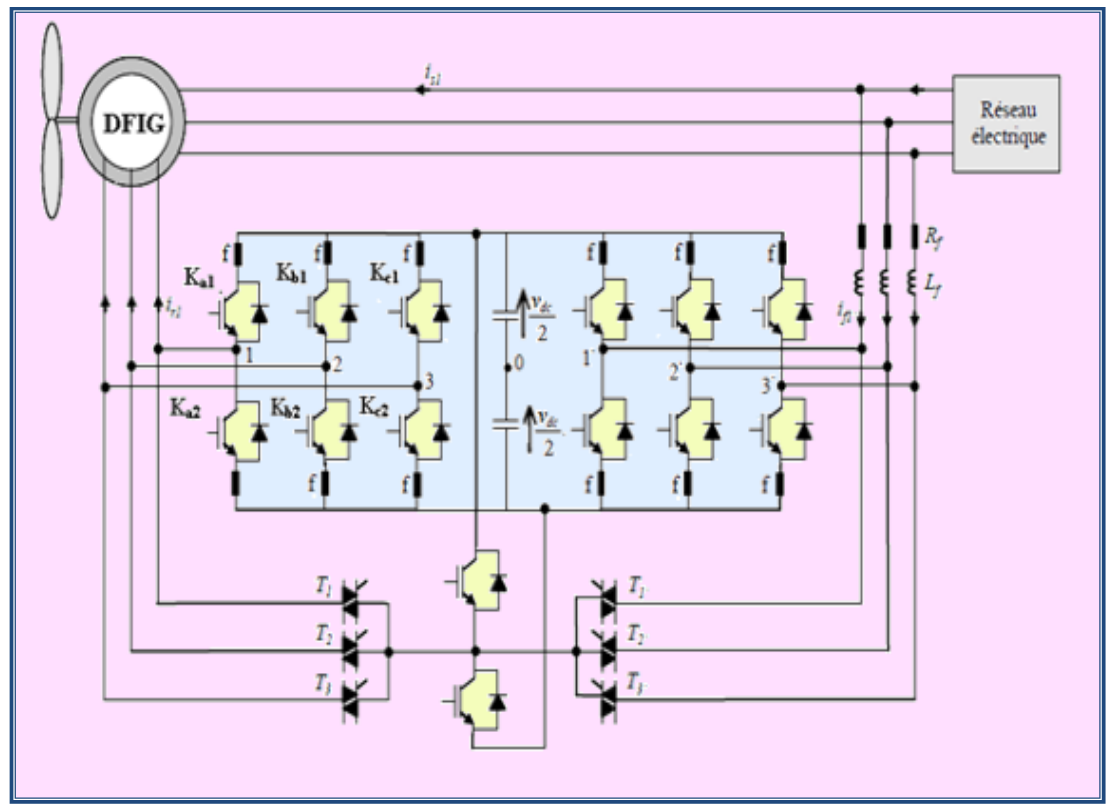

Fig. 10. Wind turbine with DFIG having floating arm

Steps that need to be followed in the occurrence of a fault are described as follows. In the event of a fault which occurs at the numbered arm $K a, b, c 1$ or $K a, b, c 2$, the continuity of service is performed according to the following steps:

\section{Segment detection}

$>$ Defective numbered arm detection

$>$ The setting of commands of the two switches of the defective arm $a, b$ or $c$ to "zero."

$>$ Closing of switches with redundant arm and application of control commands of defective arm switches to both switches of the redundant arm

$>$ Stop the "fault detection" function as only one fault can be compensated 


\section{Conclusion}

In this paper, a methodology for identifying the short circuit fault in a power switch within the power converter of the rotor-side wind power system has been proposed. This approach enables the wind system to operate in normal mode despite the occurrence of a defect and thus ensuring the continuity of its service. This fault detection method reduces significantly the detection time compared to other schemes published to date. Indeed, a possible short-circuit fault is detected only by the recognition of the shape of the voltage vector trajectory in the $\alpha-\beta$ reference at the output of the rotor side converter. Simulation results have been used to analyze this defect detection method. As the configuration and the conventional control of the threephase converters do not provide the continuity of service for the wind turbine in the event of short-circuit faults in one of the converter components, these defects can lead to a malfunction of the system or cause its disconnection from the network. Consequently, a robust fault-tolerant wind energy system has been proposed, in which the rapid detection and identification of faults result in the decommissioning of faulty arms and the connection of a floating arm in place of the defective arm, thus ensuring continuity of service.

\section{References}

[1] Reve, "Wind Power Capacity Reaches 539 GW, 52,6 GW added in 2017," Evwind, 12 February 2018. https://www.evwind.es/2018/02/12/wind-power-capacity-reaches-539-gw526-gw-added-in-2017/62587

[2] F. Richardeau, J. Mavier, H. Piquet, G. Gateau, "Fault-tolerant inverter for on-board aircraft EHA," 2007 European Conference on Power Electronics and Applications, 2007, pp. 1-9. https://doi.org/10.1109/EPE.2007.4417537

[3] R. L. A. Ribeiro, F. Profumo, C. B. Jacobina, G. Griva, E. R. C. da Silva, A. M. N. Lima, and G. Penneta, "Two fault tolerant control strategies for shunt active power filter systems," IEEE 2002 28th Annual Conference of the Industrial Electronics Society, IECON 02, 2002, pp. 792-797, vol. 1. https://doi.org/10.1109/IECON.2002.1187609

[4] M. A. Shamsi-Nejad, B. N. Mobarakeh, S. Pierfederici, F. Meibody-Tabar, "Fault tolerant and minimum loss control of double-stars synchronous machines under open phase conditions," IEEE Transactions on Industrial Electronics, vol. 55, No. 5, pp. 1956-1965, 2008. https://doi.org/10.1109/TIE.2008.918485

[5] F. Abrahamsen, F. Blaabjerg, K. Ries, K. H. Rasmussen, "Fuse Protection of IGBT's against Rupture," In Proc. 2000 IEEE Nordic Workshop on Power and Industrial Electronics Aalborg, Denmark, pp. 64-68, 2000. https://vbn.aau.dk/en/publications/fuse-protection-of-igbts-against-rupture

[6] B. Frede, I. Florin, and R. Karsten, "Fuse protection of IGBT modules against explosions," Journal of Power Electronics, vol. 2, No. 2, pp. 88-94, 2002. https://jpels.org/digital-library/16808

[7] J. Vallon, "Introduction à l'étude de la fiabilité des cellules de commutation à IGBT sous fortes contraintes," Thèse de Doctorat de l'Institut National Polytechnique de Toulouse, 2003. https://oatao.univ-toulouse.fr/7348/

[8] A. Gaillard, P. Poure, S. Saadate, "Reconfigurable Control and Converter Topology for Wind Energy Systems with Switch Failure Fault Tolerance Capability," 2009 IEEE Energy Conversion Congress and Exposition, 2009, pp. 390- 397. https://doi.org/10.1109/ECCE.2009.5316078

[9] J. Yao, J. Pei, D. Xu, R. Liu, X. Wang, C. Wang, and Y. Li, "Coordinated control strategy for a hybrid wind farm with DFIG and PMSG under symmetrical grid faults," Renewable Energy, vol. 127, pp. 613-629, 2018. https://doi.org/10.1016/j.renene.2018.04.080

[10] S. Yu, T. Fernando, K. Emami, and H. H. Iu, "Dynamic state estimation based control strategy for DFIG wind turbine connected to complex power systems," IEEE Trans. Power Syst., vol. 32, no. 2, pp. 1272-1281, 2017. https://doi.org/10.1109/TPWRS.2016.2590951

[11] S. Kumar and A. Kumar, "Reactive Power Control of Doubly Fed Induction Generator based Wind Turbine," International Journal on Future Revolution in Computer Science \& Communication $\begin{array}{lllllll}\text { Engineering, } & \text { vol. } & 4, & \text { no. } & 3, & \text { pp. } & 190-194,\end{array}$ 
http://www.ijfrcsce.org/download/conferences/ICETEST_2018/ICETEST_Track/1520920309_ 13-03-2018.pdf

[12] O. Zamzoum, Y. El Mourabit, M. Errouha, A. Derouich, A. El Ghzizal, "Active and Reactive Power Control of Wind Turbine based on Doubly Fed Induction Generator using Adaptive Sliding Mode Approach," International Journal of Advanced Computer Science and Applications (IJACSA), vol. 10, no. 2, pp. 397-406, 2019. https://doi.org/10.14569/IJACSA.2019.0100252

[13] H. S. Salama and I. Vokony, "Power Stability Enhancement of SCIG and DFIG Based Wind Turbine Using Controlled-SMES," International Journal of Renewable Energy Research (IJRER), vol. 9, no. 1, pp. 147-156, 2019. https://www.ijrer.ijrer.org/index.php/ijrer/article/view/8817

[14] S. Janarthanan, "Analysis of Grid Connected DFIG based Wind Farms for Reactive Power Compensation," International Journal of Latest Technology in Engineering, Management \& Applied Science (IJLTEMAS), vol. 6, no. 6, pp. 2278-2540, 2017. https://www.ijltemas.in/DigitalLibrary/Vol.6Issue6/198-202.pdf

[15] L V. Dai and D. D. Tung, "Modeling for Development of Simulation Tool: A Case Study of Grid Connected Doubly Fed Induction Generator Based on Wind Energy Conversion System," International Journal of Applied Engineering Research, vol. 12, no. 11 pp. 2981-2996, 2017. https://www.ripublication.com/ijaer17/ijaerv12n11_50.pdf

[16] S. Ghoudelbourk, A. Omeiri, and A. Guebla, "Improving the quality of energy supplied by a doublefed induction generator fed by multilevel inverters," 2014 9th International Symposium on Communication Systems, Networks \& Digital Sign (CSNDSP), 2014, pp. 787-792. https://doi.org/10.1109/CSNDSP.2014.6923934

[17] S. Ghoudelbourk, D. Dib, and A. Omeiri, "Decoupled control of active and reactive power of a wind turbine based on DFIG and matrix converter," Energy System, vol. 7, pp. 483-497, 2016. https://doi.org/10.1007/s12667-015-0177-1 